\title{
Colloid Science of Metal Nanoparticle Catalysts in 2D and 3D Structures. Challenges of Nucleation, Growth, Composition, Particle Shape, Size Control and their Influence on Activity and Selectivity
}

\author{
Gabor A. Somorjai ${ }^{1,2, *}$ and Jeong Y. Park ${ }^{1,2}$ \\ ${ }^{1}$ Department of Chemistry, University of California, Berkeley, CA 94720 \\ ${ }^{2}$ Materials Sciences Division and Chemical Sciences Division, Lawrence Berkeley National \\ Laboratory, Berkeley, CA 94720
}

* To whom correspondence should be addressed. E-mail: somorjai@ berkeley.edu.

Recent breakthroughs in synthesis in nanosciences have achieved control of size and shapes of nanoparticles that are relevant for catalyst design. In this article, we review the advance of synthesis of nanoparticles, fabrication of two and three dimensional model catalyst system, characterization, and studies of activity and selectivity. The ability to synthesize monodispersed platinum and rhodium nanoparticles in the 1-10 $\mathrm{nm}$ range permitted us to study the influence of composition, structure, and dynamic properties of monodispersed metal nanoparticle on chemical reactivity and selectivity. We review the importance of size and shape of nanoparticles to determine the reaction selectivity in multi-path reactions. The influence of metal-support interaction has been studied by probing the hot electron flows through the metal-oxide interface in catalytic nanodiodes. Novel designs of nanoparticle catalytic systems are discussed. 


\section{Introduction - Evolution of catalyst model system}

It rarely happens in the history of catalysis that new catalyst materials and structures are invented that lead to the development of new catalytic reactions and new chemical and energy conversion processes. Nanosciences and the synthesis of monodispersed nanoparticles present this opportunity. Most industrial heterogeneous catalysts are highly dispersed metal nanoparticles supported on porous oxides ${ }^{[1-5]}$. Recent breakthroughs in synthesis in nanosciences have achieved control of size and shapes of nanoparticles ${ }^{[1,6-11]}$. The influence of composition, structure, and dynamic properties of monodispersed metal nanoparticles on chemical reactivity and selectivity have been studied to bridge the so called "material gaps" [4-6, 9, 10, 12-14].

In this article, we review the evolution of model catalysts over the past 10 years that are moving from studies of single crystal surfaces to nanoparticles fabricated by colloid synthesis. The evolution of model catalyst systems are shown in Figure 1. Single crystal surfaces have served as model catalytic systems that have shed light on many surface phenomena. However, single crystal surfaces inherently lack the complexity needed to uncover many of the factors important to catalytic turnover and selectivity for industrial catalysis. To consider these factors such as metal support interactions and the importance of metallic cluster size, new catalytic model systems have been suggested. Figure 1 shows two of suggested emerging model systems that are colloid nanoparticles with control of size and shape on two or three dimensional supports.

To fabricate two-dimensional (2D) or three-dimensional (3D) nanoparticle arrays, we deposit nanoparticles arrays on the planar support, or encapsulate them in three 
dimensional mesoporous support, and carry out characterization and catalytic studies in these modes. Colloid techniques are used to take chloroplatinic acid or a rhodium precursor like rhodium acetyl/acetonate, and in the presence of a polymer (PVP) these metal ions are reduced in alcohol ${ }^{[10,11,15,16]}$. As the particle nucleate and grow they are kept with a polymer that is porous enough to allow growth to various sizes from 1-8 nm as shown in Fig $2 \mathrm{a}$. Not only can we control the particle size by the monomer concentration, but with suitable change of the growth parameters we can change the shape of these particles from hexagonal to cubic, to a mixture of cubic and hexagonal called cuboctahedra as shown in Figure $2 b^{[8,17}$ l.

Once we have obtained monodispersed particles with desired size and shape we can put it on a Langmuir trough and squeeze it with a certain surface pressure to deposit different densities of monolayer films of these nanoparticles. The average inter-particle spacing can be tuned by varying surface pressure as shown in Fig $3^{[10,11]}{ }^{[18]}$. This approach has the advantage of size and shape control of the nanoparticles synthesized with this colloidal route and the formation of an oxide-metal interface between nanoparticles and substrate. Various surface techniques such as X-ray photoelectron spectroscopy (XPS) and atomic force microscopy (AFM) can be utilized to characterize the chemical composition and morphology of 2D nanoparticle arrays before and after the chemical reactions.

Colloid nanoparticles can also be used in 3D model catalysts. The 3D nanoparticle systems have high surface area $\sim 1 \mathrm{~m}^{2} / \mathrm{g}$, oxide/metal interfaces that closely resemble industrial systems, and controllable size and shape. We can encapsulate the nanoparticles with mesoporous support as SBA-15 silica. Figure 4 shows the TEM image of Pt nanoparticles $(2.6 \mathrm{~nm})$ assembled into SBA-15 silica support via the method of synthesis 
called capillary inclusion. In this method, monodispersed Pt nanoparticles and mesoporous SBA-15 silica are mixed in water/ethanol solution with low power sonication to promote nanoparticle entry into the SBA-15 pore structure by capillary inclusion and mechanical agitation ${ }^{[10]}$. The other method of $3 \mathrm{D}$ catalyst synthesis involves the hydrothermal synthesis of SBA-15 silica in a solution containing polymer stabilized Pt nanoparticles. This method, referred to as nanoparticle encapsulation (NE) leads to Pt/SBA-15 catalysts with particles located within the silica pore structure ${ }^{[11]}$.

\section{Chemical activity studies of $2 \mathrm{D}$ and $3 \mathrm{D}$ nanoparticle systems}

Below the activity studies are shown by several examples. Ammonia synthesis is very structure sensitive ${ }^{[19,20]}$. Spencer et al. studied ammonia formation on five different faces of iron single crystals at $798 \mathrm{~K}$ and a total pressure of 20 atm of a stoichiometric mixture of hydrogen and nitrogen, and found that the (111) face is the most active face. This structure sensitivity leads to an increase of turnover rate for ammonia formation as the iron nanoparticle size is increased as shown in Figure 5, because the (111) surface is preferential as the particle size increases ${ }^{[19-21]}$.

Song et al. studied the dependence of the turnover rate and activation energy on the Pt particle size under ethylene hydrogenation and ethane hydrogenolysis. Monodisperse platinum nanoparticles of 1.7-7.1 nm have been synthesized by alcohol reduction methods and incorporated into mesoporous SBA-15 silica during hydrothermal synthesis. Figure 6 shows the plot of turnover rate and activation energy of ethylene hydrogenation over Pt nanoparticles and single crystals as a function of particle size under ethylene hydrogenation, 
indicating that the turnover rates are unchanged with the size of Pt nanoparticle along with the activation energy, which remains constant. All data were taken at or corrected to $298 \mathrm{~K}$, 10 Torr $\mathrm{C}_{2} \mathrm{H}_{4}, 100$ Torr $\mathrm{H}_{2} .{ }^{[11,22]}$ For ethane hydrogenolysis to methane the turnover rate declines with particle size while the activation energy increases as shown in Figure 7. [11] Turnover frequencies decrease by 2 orders of magnitude over the size range, while the apparent activation energy increases. Coordinatively unsaturated surface atoms in small particles have a higher reactivity and subsequently a smaller barrier for hydrogenolysis than highly coordinated surface atoms of larger particles.

For cyclohexene hydrogenation to cyclohexane over platinum nanoparticles again the turnover rate and the activation energy remains unchanged with increasing particle size (figure 8a). However, for cyclohexene dehydrogenation to benzene the turnover rate declines markedly as the activation energy increases the particle size (figure 8b). Crotonaldehyde hydrogenation shows steady state turnover with increasing particle size along with unchanged activation energies (figure 9).

\section{Catalyst Characterization under Reaction Conditions}

Techniques of surface science allow us to determine the reaction intermediate under catalytic reaction conditions along with the surface mobility ${ }^{[14,23]}$. The high pressure scanning tunneling microscopy allows us to look at surface mobility (figure 10a) ${ }^{[24-28]}$, while sum frequency generation vibrational spectroscopy allows us to measure the vibrational spectra of adsorbed molecules $^{[29-31]}$ (figure 10b). Figure 11a shows that during cyclohexene hydrogenation/dehydrogenation the three species on the catalytically active 
surfaces are 1,3 cyclohexadiene $\pi$-allyl and 1,4 cyclohexadiene $^{[32]}$. During the reaction scanning tunneling microscopy at high pressure show no sign of order on the catalytic reactive surface. The mobility of the adsorbate must be greater than 100 Á per millisecond to make it impossible to exhibit ordered structure (figure 11b). However, when the reaction is poisoned by the introduction of carbon monoxide ordered structure forms and the catalytic turnover stops (figure 11c) ${ }^{[26]}$. Thus the mobility is an important feature of the catalytically reactive surface as the adsorbate has to be mobile in order to turn over. Not only the adsorbates are mobile but the substrate metal is mobile. We found that the (110) surface of platinum undergoes restructuring in different ways in the presence of atmospheric hydrogen

or oxygen of carbon monoxide ${ }^{[33]}$. The restructuring of the surface coincides with the mobility of the adsorbate, thus the surface, both the metal and the adsorbate, has to be dynamic for catalytic reactions to occur.

\section{Reaction selectivity on nanoparticle systems}

In the $21^{\text {st }}$ Century catalysis science focuses on reaction selectivity. That is, if there are several thermodynamically stable products that we only want to form the one desired product out of several products. We have investigated some typical multipath reactions selectivity; benzene, cyclohexene and crotonaldehyde. The reaction selectivity is much less understood than the reaction activity of single product catalytic reaction such as ammonia synthesis or ethylene hydrogenation. A very small change in competing potential energy barriers due to structure, or the use of additives changes the product selectivity dramatically. We studied this reaction in the form on benzene hydrogenation which produces two 
molecules; cyclohexane and cyclohexene on the platinum (111) surface while only one molecule (cyclohexene) on the (100) face. What we find is that nanoparticles, when they are cuboctahedra, give rise to two products just like (111) single crystal surfaces, but when they are cubes they give rise to one product like the (100) single crystal surface (figure 12) [17]. The reaction selectivity for cyclohexene hydrogenation/dehydrogenation favors cyclohexene formation as the particle size increases while benzene formation declines (figure 13). The reason for this is that while the activation energy for hydrogenation of cyclohexene to cyclohexane is constant as a function of particle size and remains unchanged, the activation energy for dehydrogenation to benzene increases with increasing particle size that results in declining benzene concentrations.

Figure $14 \mathrm{a}$ shows the schematic of multi-path reactions of crotonaldehyde hydrogenation. As shown in Figure 14b, the sum total of butyraldehyde and crotyl alcohol, the two products of crotonaldehyde hydrogenation, is constant the selectivity changes with particle size as small nanoparticles of platinum favor butyraldehyde while larger particle sizes favor crotyl alcohol to form.

\section{Novel nanoparticle assembly for the nanocatalysis}

The field of nanocatalysis is therefore established whereby nanoparticles nucleation growth. Characterization and formation of either two-dimensional or three-dimensional assemblies are the basis for nanocatalysis followed by studies of reaction selectivity and activity. Nanoparticle synthesis studies indicate the formation of bimetallic nanoparticles,

and several of these are shown in Fig. 15. We can make palladium nanoparticles using 
platinum nanoparticles as seeds (Fig. 15a) ${ }^{[34]}$ iron platinum (Fig. 15b) and cobalt platinum (Fig. 15c) bimetallic materials. ${ }^{[35,36]}$ These structures can be synthesized by using monodispersed nanoparticles as seeds for nucleating the second component of nanoparticle. The bimetallic nanoparticle structure allows maximization of the density of interface sites and permits tailoring the composition of multicomponent catalytic systems with high level of precision. Such structures can exhibit interesting properties because of assembling two different catalysts into one nanoscale unit with well-defined and easily accessible boundary between two materials.

There is another type of nanoparticles called core shell structures, which is based on the Kirkendall effect. That is when two substances diffuse to form a compound, one diffuses must faster than the other one as shown in the figure 16. Zinc and copper form brass, but zinc diffuses must faster than copper leaving behind zinc vacancies ${ }^{[37]}$. Nanoparticles of cobalt can be made hollow by forming a sulfide or an oxide as the shell and the cobalt diffuses out faster than the sulfur or oxygen diffuses in, forming a hollow nanocrystal as shown in Fig. $16^{[38]}$. We can use this phenomenon to provide a shell of cobalt oxide around a platinum seed. Iron oxide shells around gold or iron oxide shells around iron have been all synthesized as shown in Fig. 17 by a three-step process ${ }^{[38]}$. Platinum particles were synthesized first, followed by injection and decomposition of $\mathrm{Co}_{2}(\mathrm{CO})_{8}$ to form $\mathrm{Pt} / \mathrm{Co}$ coreshell nanoparticles, and the introduction of oxygen to transform the Co into $\mathrm{CoO}$ hollow structures. The resulting material is a hollow $\mathrm{CoO}$ shell with a Pt nanoparticle in the interior. Formation of hollow nanostructures via Kirkendall effect was observed for a number of materials, including $\mathrm{Co} / \mathrm{Co}_{9} \mathrm{~S}_{8}, \mathrm{Co} / \mathrm{CoO}, \mathrm{Pt} / \mathrm{CoO} . \mathrm{Ag} / \mathrm{Au}$, and $\mathrm{Fe} / \mathrm{Fe}_{\mathrm{x}} \mathrm{O}_{\mathrm{y}}$. 
In most cases the hollow exterior shell is polycrystalline, and selected small molecules are thought to enter the internal cavity via grain boundaries and pinholes. When encapsulated in this manner, the interior nanoparticles retain their catalytic activity, as was

demonstrated by Yin et al for the ethylene hydrogenation reaction ${ }^{[38]}$. Encapsulated catalyst nanoparticles should be much more resistant to aggregation and sintering. Small average diameter of the pinholes for reactant access and product removal provides a means for molecular shape selectivity. Size and shape selectivity is expected for molecules with average cross-sections less than the pinhole diameter. By performing reaction in a confined medium we also expect to improve the selectivity of hydrocarbon conversion reactions used as liquid fuels.

The core-shell nanoparticles combining oxide and transition metal can be synthesized in a similar manner. Metal oxides such as $\mathrm{ZnO}, \mathrm{MnO}_{2}, \mathrm{TiO}_{2}, \mathrm{Fe}_{3} \mathrm{O}_{4}$ can be combined with transition metals ( $\mathrm{Pt}, \mathrm{Pd}, \mathrm{Ru}, \mathrm{Ni}, \mathrm{Co}, \mathrm{Fe}, \mathrm{Au}, \mathrm{Cu})$ and used to investigate the catalytic activity and selectivity. The metal-oxide interface is known to be the active site responsible for the increased reaction rates in many industrial catalysts ${ }^{[39,40]}$. However, characterization and control of these interfaces has been challenging, limiting prospects for optimizing catalytic activity. The development and investigation of well-defined, multicomponent nanoparticle system with the control of size and shape by colloidal chemistry techniques are key issue in the nanocatalysis.

\section{The active sites at the oxide metal interface}


Studies indicate that when a catalytically active metal is covered with an oxide that carries out no catalytic reaction, the metal becomes much more active. These studies were initiated in the 1950's and 1960's and an explanation for this phenomenon is provided by the evidence of hot electron generation at metal surfaces ${ }^{[41]}$. It appears that when photons strike a metal surface in the femtosecond regime hot electrons generate and diffused into the metal before they can be equilibrated with lattice vibrations. The diffusion mean free pass could be around 5-10 nm. Also, when vibrationally excited molecules strike another surface they are rapidly deexcited because of hot electron formation ${ }^{[42-44]}$. We fabricated a catalytic nanodiode where catalytically reactive platinum thin films were deposited on an oxide to form a Schottky barrier and we made contact to both sides of this barrier of $\mathrm{Pt}$ or $\mathrm{Pd}$ on $\mathrm{TiO}_{\mathrm{x}}$ or $\mathrm{GaN}^{[45-47]}$. Figure 18a shows the typical $\mathrm{I}-\mathrm{V}$ curves measured on $\mathrm{Pd} / \mathrm{TiO}_{\mathrm{x}}$ diode. We fabricated 18 of these diodes on a silicon 4 inch wafer and then enclosed it into a catalytic reactor where we can measure both the current and the product distribution of the gas phase reactions, which was in this case carbon monoxide oxidation. As one sees in the Fig. 18b, the chemicurrent is proportional to the turnover rate of the catalytic reaction indicating that the two correlates and coincides ${ }^{[48]}$. More importantly, we found that application of a electrostatic potential between the metal and the oxide under the reaction condition influences the turnover rate. The mechanism of influence of hot electron flows on the catalytic activity is being investigated. This provides a glimpse of the possibility that by using hot electrons flow we can control turnover, while the turnover of the exothermic reaction provides the hot electron currents.

\section{Future perspective - Catalysts are all nanoparticles}


Whether we look at enzyme catalysts, homogeneous or heterogeneous catalysts they are all nanoparticles. The Figure 19a shows cytochrome $\mathrm{C}$ which has a $4 \mathrm{~nm}$ size where the catalytic site outside the protein ligands are $1.4 \mathrm{~nm}$ in size. A single site olefin

polymerization catalyst (figure 19b), which is homogeneous, has a $1.6 \mathrm{~nm}$ size ${ }^{[49]}$. A platinum nanoparticle can be produced and are active in the 1-7 $\mathrm{nm}$ regime. This shows that nature and technology prefers catalysts which are all in the nanoparticle size range and to understand them we have to be able to study them under the same reaction conditions if at all possible to learn the molecular ingredients that are responsible for the catalytic activity. This, we believe, will be one of the major directions of research in the near future.

\section{Acknowledgement}

This work was supported by the Director, Office of Science, Office of Basic Energy Sciences, Division of Materials Sciences and Engineering of the U.S. Department of Energy under Contract No. DE-AC02-05CH11231. 


\section{References}

[1] A. Roucoux, J. Schulz and H. Patin, Chemical Reviews 2002, 102, 3757-3778.

[2] N. Tian, Z. Y. Zhou, S. G. Sun, Y. Ding and Z. L. Wang, Science 2007, 316, 732-735.

[3] A. T. Bell, Science 2003, 299, 1688-1691.

[4] R. M. Rioux, H. Song, M. Grass, S. Habas, K. Niesz, J. D. Hoefelmeyer, P. Yang and G.

A. Somorjai, Topics in Catalysis 2006, 39, 167-174.

[5] G. A. Somorjai and R. M. Rioux, Catalysis Today 2005, 100, 201-215.

[6] H. J. Freund, H. Kuhlenbeck, J. Libuda, G. Rupprechter, M. Baumer and H. Hamann, Topics in Catalysis 2001, 15, 201-209.

[7] R. Narayanan and M. A. El-Sayed, Nano Letters 2004, 4, 1343-1348.

[8] H. Lee, S. E. Habas, S. Kweskin, D. Butcher, G. A. Somorjai and P. D. Yang, Angewandte Chemie-International Edition 2006, 45, 7824-7828.

[9] K. Niesz, M. Grass and G. A. Somorjai, Nano Letters 2005, 5, 2238-2240.

[10] R. M. Rioux, H. Song, J. D. Hoefelmeyer, P. Yang and G. A. Somorjai, Journal of Physical Chemistry B 2005, 109, 2192-2202.

[11] H. Song, R. M. Rioux, J. D. Hoefelmeyer, R. Komor, K. Niesz, M. Grass, P. D. Yang and G. A. Somorjai, Journal of the American Chemical Society 2006, 128, 3027-3037.

[12] G. A. Somorjai and J. Y. Park, Catalysis Letters 2007, 115, 87-98.

[13] G. A. Somorjai and J. Y. Park, Physics Today 2007, 60, 48-53.

[14] G. A. Somorjai, R. L. York, D. Butcher and J. Y. Park, Physical Chemistry Chemical Physics 2007, 9, 3500-3513.

[15] S. M. Humphrey, M. E. Grass, S. E. Habas, K. Niesz, G. A. Somorjai and T. D. Tilley, Nano Letters 2007, 7, 785-790.

[16] Y. Zhang, M. E. Grass, S. E. Habas, F. Tao, T. Zhang, P. Yang and G. A. Somorjai, Journal of Physical Chemistry C 2007, 111, 12243-12253.

[17] K. M. Bratlie, H. Lee, K. Komvopoulos, P. Yang and G. A. Somorjai, Nano Letters 2007, 7, 3097-3101.

[18] H. Song, F. Kim, S. Connor, G. A. Somorjai and P. D. Yang, Journal of Physical Chemistry B 2005, 109, 188-193.

[19] M. Boudart and D. G. Loffler, Journal of Physical Chemistry 1984, 88, 5763-5763.

[20] N. D. Spencer, R. C. Schoonmaker and G. A. Somorjai, Journal of Catalysis 1982, 74, $129-135$.

[21] H. Topsøe, N. Topsøe, H. Bohlbro and J. A. Dumesic, in:Proc. 7th Int. Congr. on Catalysis, Part A, eds. T. Seiyama and K. Tanabe (Kodansha, Tokyo, 1981) p. 247.

[22] F. Zaera and G. A. Somorjai, Journal of the American Chemical Society 1984, 106, 2288-2293.

[23] G. A. Somorjai, K. M. Bratlie, M. O. Montano and J. Y. Park, Journal of Physical Chemistry B 2006, 110, 20014-20022.

[24] B. L. M. Hendriksen and J. W. M. Frenken, Physical Review Letters 2002, 89.

[25] J. A. Jensen, K. B. Rider, M. Salmeron and G. A. Somorjai, Physical Review Letters 1998, 80, 1228-1231.

[26] M. Montano, M. Salmeron and G. A. Somorjai, Surface Science 2006, 600, 1809-1816.

[27] L. Osterlund, P. B. Rasmussen, P. Thostrup, E. Laegsgaard, I. Stensgaard and F. Besenbacher, Physical Review Letters 2001, 86, 460-463. 
[28] D. C. Tang, K. S. Hwang, M. Salmeron and G. A. Somorjai, Journal of Physical Chemistry B 2004, 108, 13300-13306.

[29] K. M. Bratlie, C. J. Kliewer and G. A. Somorjai, Journal of Physical Chemistry B 2006, 110, 17925-17930.

[30] Y. R. Shen, Annual Review of Physical Chemistry 1989, 40, 327-350.

[31] X. C. Su, P. S. Cremer, Y. R. Shen and G. A. Somorjai, Physical Review Letters 1996, 77, 3858-3860.

[32] K. M. Bratlie, L. D. Flores and G. A. Somorjai, Surface Science 2005, 599, 93-106.

[33] B. J. McIntyre, M. Salmeron and G. A. Somorjai, Journal of Vacuum Science \& Technology a-Vacuum Surfaces and Films 1993, 11, 1964-1968.

[34] S. E. Habas, H. Lee, V. Radmilovic, G. A. Somorjai and P. Yang, Nature Materials 2007, 6, 692-697.

[35] E. V. Shevchenko, D. V. Talapin, A. L. Rogach, A. Kornowski, M. Haase and H. Weller, Journal of the American Chemical Society 2002, 124, 11480-11485.

[36] E. V. Shevchenko, D. V. Talapin, N. A. Kotov, S. O'Brien and C. B. Murray, Nature 2006, 439, 55-59.

[37] F. Aldinger, Acta Metallurgica 1974, 22, 923-928.

[38] Y. D. Yin, R. M. Rioux, C. K. Erdonmez, S. Hughes, G. A. Somorjai and A. P. Alivisatos, Science 2004, 304, 711-714.

[39] S. J. Tauster, S. C. Fung and R. L. Garten, Journal of the American Chemical Society 1978, 100, 170-175.

[40] K. Hayek, M. Fuchs, B. Klotzer, W. Reichl and G. Rupprechter, Topics in Catalysis 2000, 13, 55-66.

[41] G. M. Schwab, Angewandte Chemie-International Edition 1967, 6, 375-\&.

[42] J. W. Gadzuk, Journal of Physical Chemistry B 2002, 106, 8265-8270.

[43] L. Hellberg, J. Stromquist, B. Kasemo and B. I. Lundqvist, Physical Review Letters 1995, 74, 4742-4745.

[44] Y. H. Huang, C. T. Rettner, D. J. Auerbach and A. M. Wodtke, Science 2000, 290, 111114.

[45] X. Z. Ji, A. Zuppero, J. M. Gidwani and G. A. Somorjai, Nano Letters 2005, 5, 753-756. [46] J. Y. Park, J. R. Renzas, A. M. Contreras and G. A. Somorjai, Topics in Catalysis 2007, 46, 217.

[47] J. Y. Park and G. A. Somorjai, Chemphyschem 2006, 7, 1409-1413.

[48] J. Y. Park, J. R. Renzas, B. B. Hsu and G. A. Somorjai, Journal of Physical Chemistry C 2007, 111, 15331-15336.

[49] J. Tian, P. D. Hustad and G. W. Coates, Journal of the American Chemical Society 2001, 123, 5134-5135. 
Pt single crystal surface
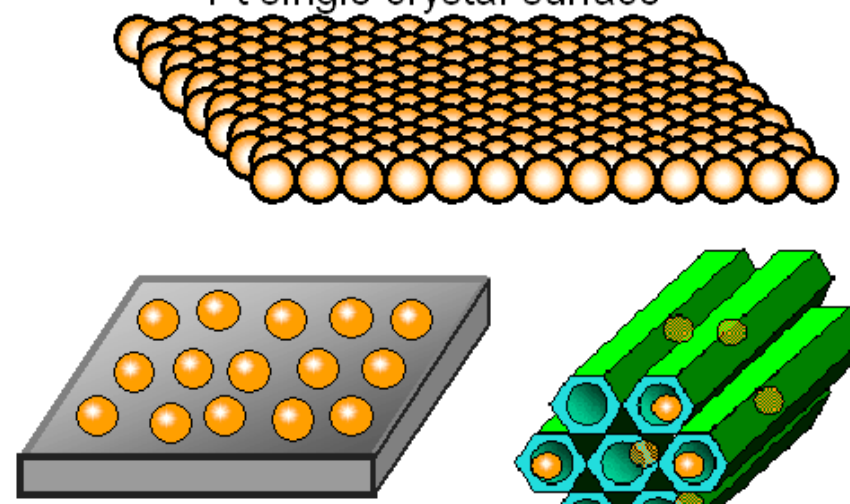

2D nanoparticle array

(1-10 $\mathrm{nm}$, disordered)

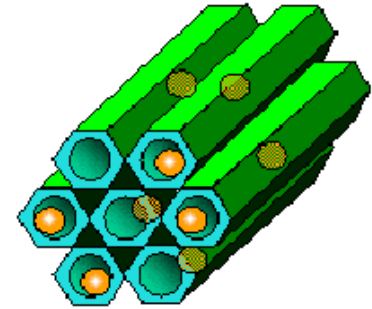

3D nanoparticle array

(high surface area)

Figure 1. Schematic showing the evolution of the catalyst model system from the single crystal metal surface to the 2D and 3D nanoparticle arrays that are composed of colloid synthesized nanoparticles and 2D and 3D oxide supports. 
(a)
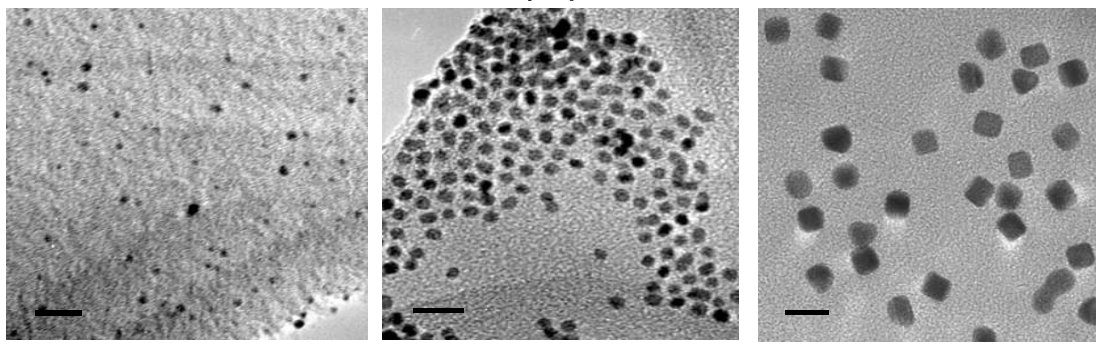

$1.73 \pm 0.26 \mathrm{~nm}$

$3.39 \pm 0.26 \mathrm{~nm}$

$7.16 \pm 0.37 \mathrm{~nm}$

(b)

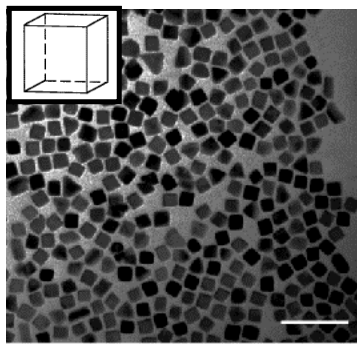

Cube

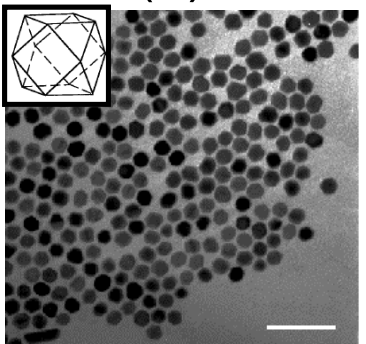

Cuboctahedra

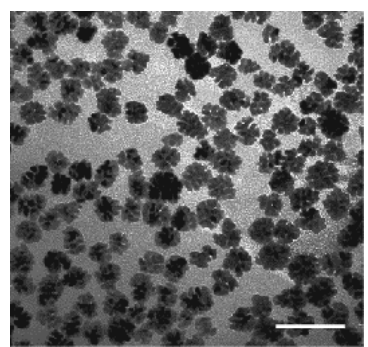

Porous particle

Figure 2. (a) TEM images of Pt nanoparticles with various sizes capped with PVP poly (vinylpyrrolidone). Size of nanoparticles can be controlled in the range of $1.7 \sim 7.1 \mathrm{~nm}$. The scale bars refer to $10 \mathrm{~nm}$. (b) TEM image of Pt nanoparticles with different shapes (cube, cuboctahedra, and porous particles) stabilized with CTAB. The scale bar in the images refer to $20 \mathrm{~nm}$. 


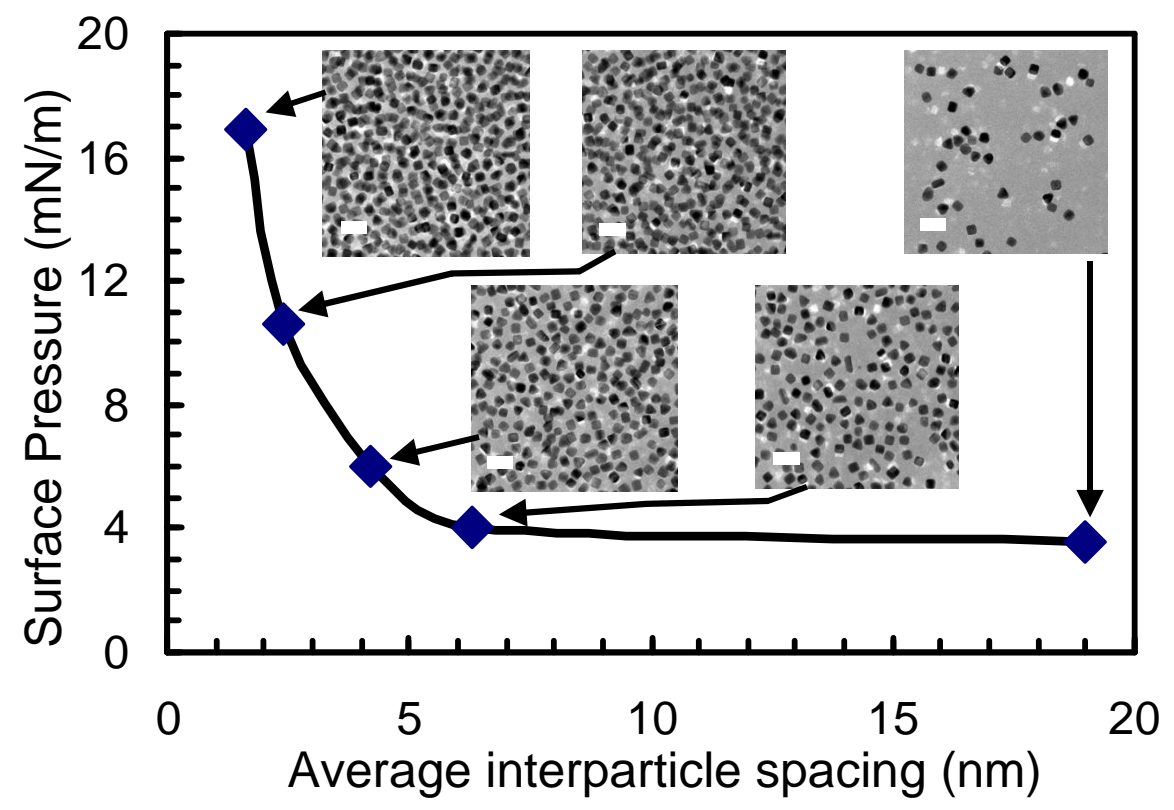

Figure 3. Plot of surface pressure as a function of average interparticle spacing of monodispersed Pt nanoparticle arrays. The surface density of nanoparticles is controlled by the surface pressure. The bars in the TEM images refer to $20 \mathrm{~nm}$. 


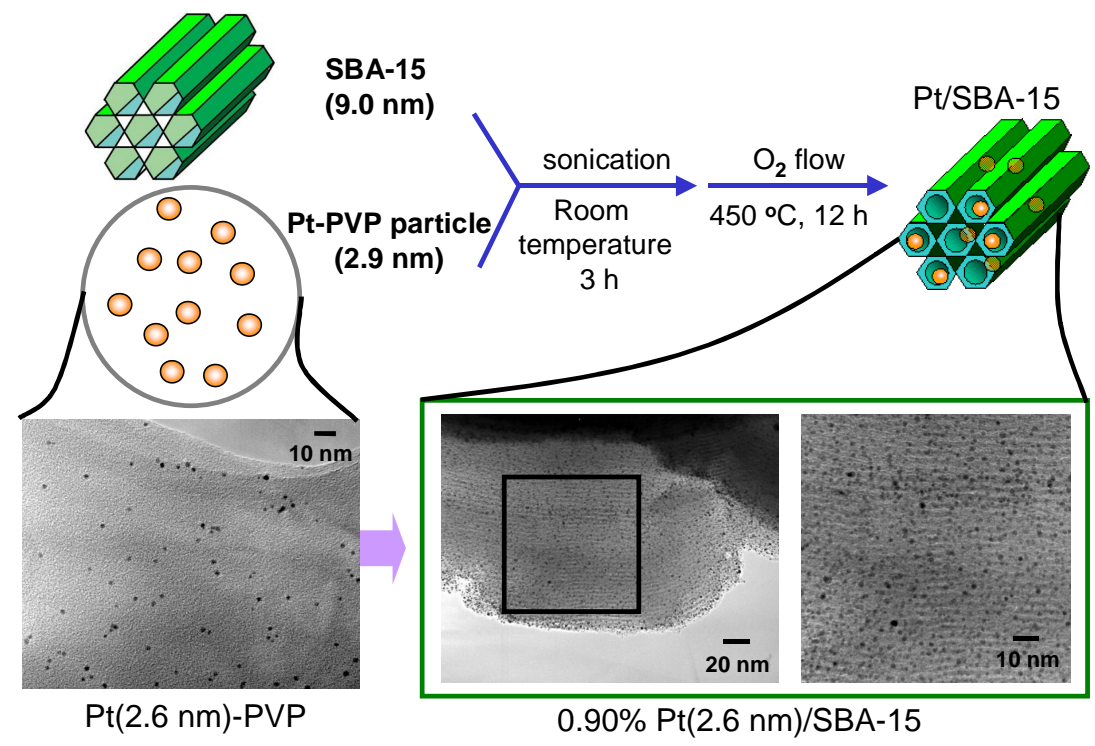

Figure 4. TEM images of Pt nanoparticles $(2.6 \mathrm{~nm})$ assembled into SBA-15 silica support by capillary inclusion method. 


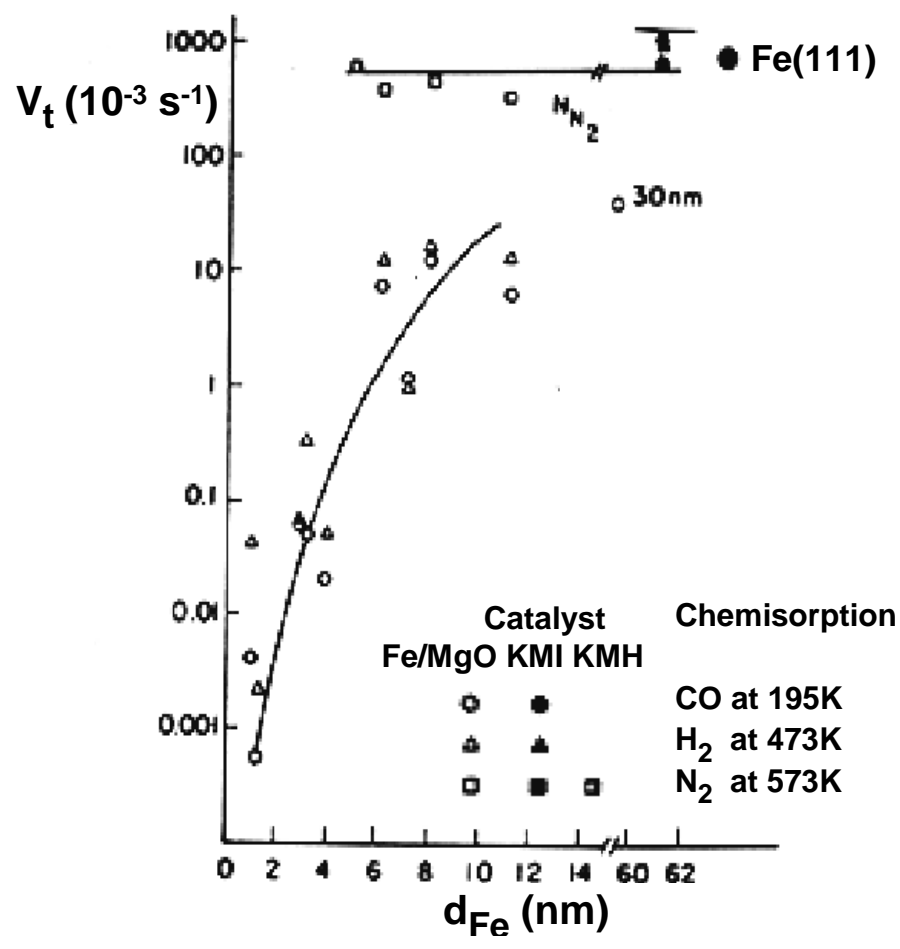

Figure 5. Turnover rate for the synthesis of ammonia as a function of $\mathrm{Fe}$ particle size. Rate of turnover rate of ammonia synthesis was measured at $673 \mathrm{~K}$, atomospheric pressure, and stichiometric mixture of 0.15 . The $\mathrm{KMI}$ and $\mathrm{KMH}$ catalysts are promoted, unsupported iron. The sites were counted by chemisorption of $\mathrm{H}_{2}, \mathrm{CO}$, or $\mathrm{N}_{2}$ as indicated. 


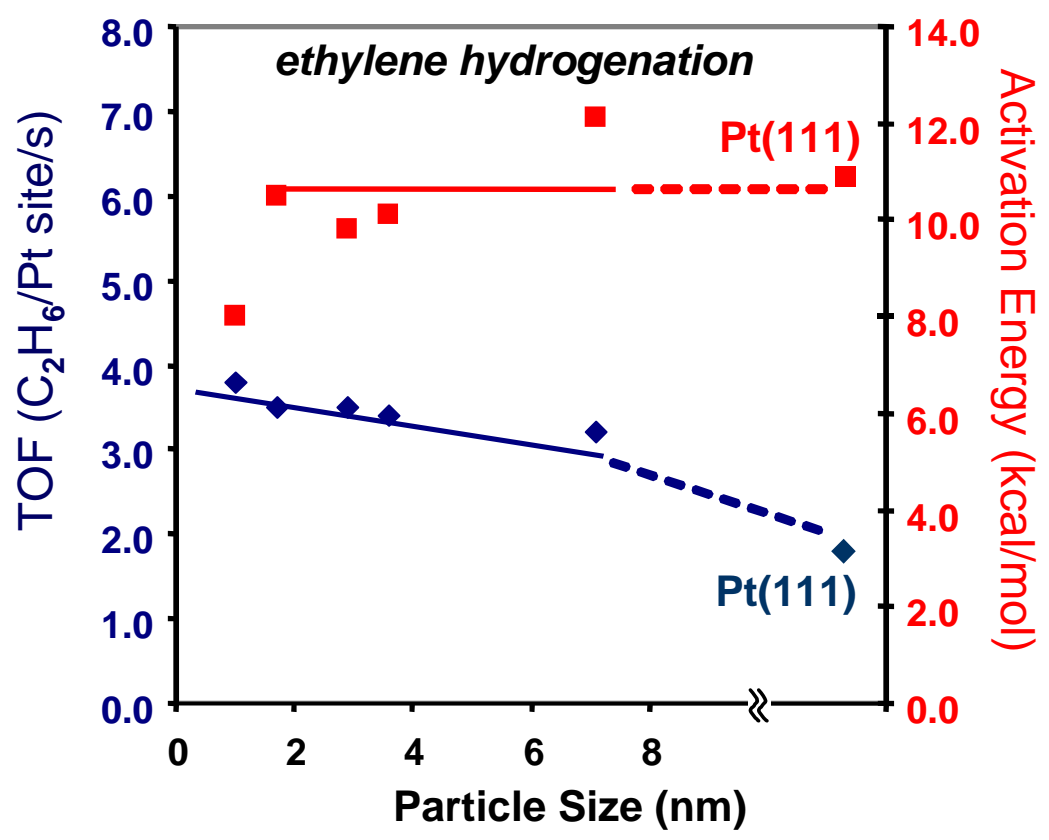

Figure 6. Turnover rate and activation energy of ethylene hydrogenation over $\mathrm{Pt}$ nanoparticles and single crystals as a function of particle size. All data were taken at or corrected to 298 $\mathrm{K}, 10$ Torr $\mathrm{C}_{2} \mathrm{H}_{4}, 100$ Torr $\mathrm{H}_{2}$. 


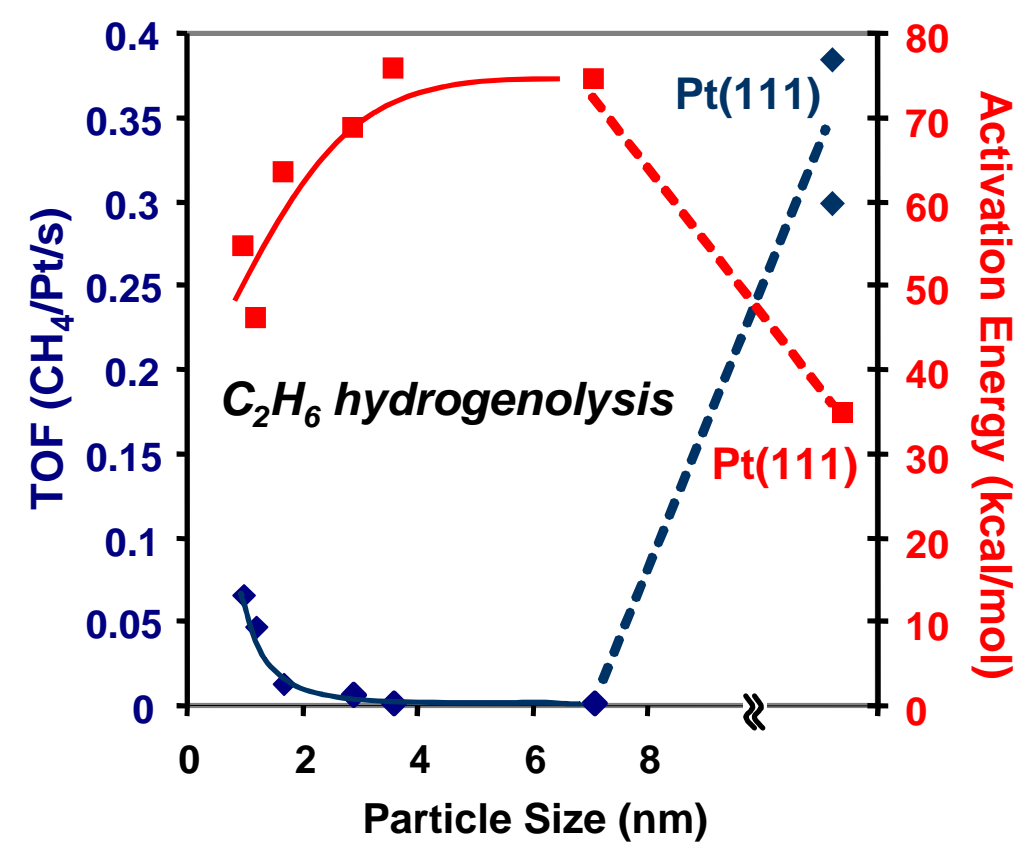

Figure 7. Turnover rate and activation energy of $\mathrm{C}_{2} \mathrm{H}_{6}$ hydrogenolysis over $\mathrm{Pt}$ nanoparticles and single crystals as a function of particle size. All data were taken at or corrected to $658 \mathrm{~K}, 20$ Torr $\mathrm{C}_{2} \mathrm{H}_{6}, 200$ Torr $\mathrm{H}_{2}$. 

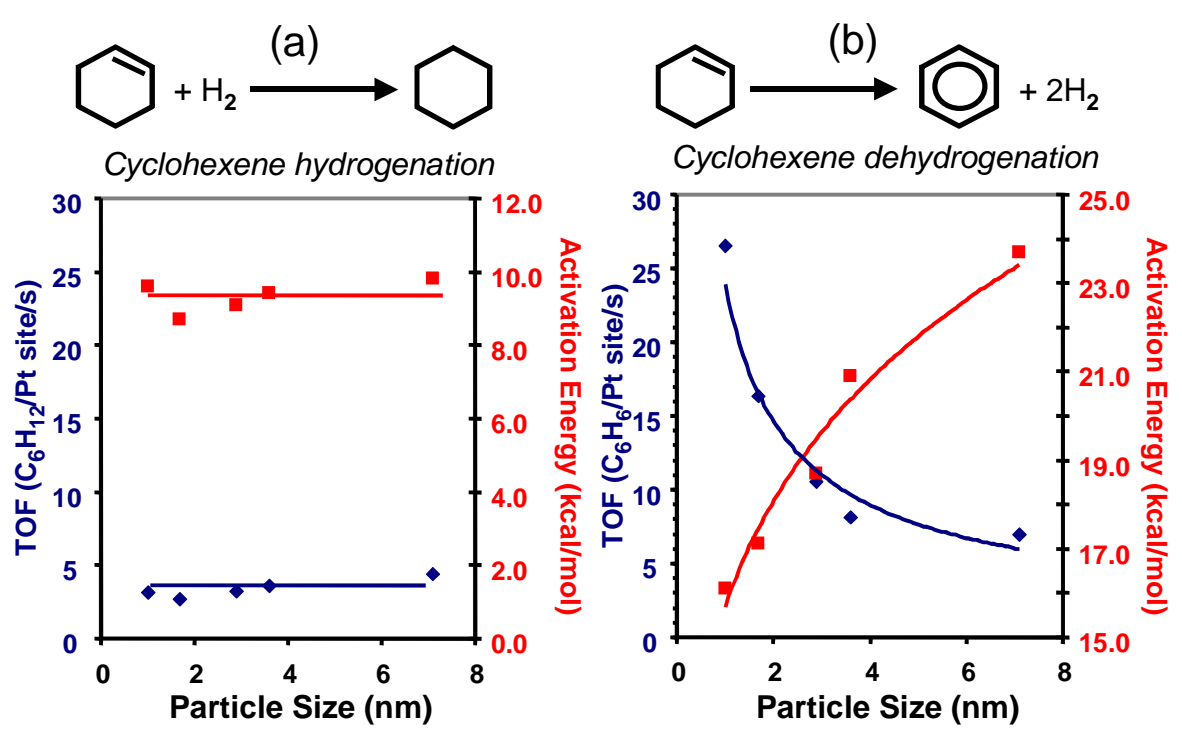

Figure 8. Turnover rate and activation energy over Pt nanoparticles as a function of particle size in (a) cyclohexene hydrogenation and (b) dehydrogenation. All data of (a) were taken at $310 \mathrm{~K}, 10$ Torr $\mathrm{C}_{6} \mathrm{H}_{10}, 200$ Torr $\mathrm{H}_{2}$, steady state, and (b) were taken $448 \mathrm{~K}, 10$ Torr $\mathrm{C}_{6} \mathrm{H}_{10}, 200$ Torr $\mathrm{H}_{2}$, steady state. 


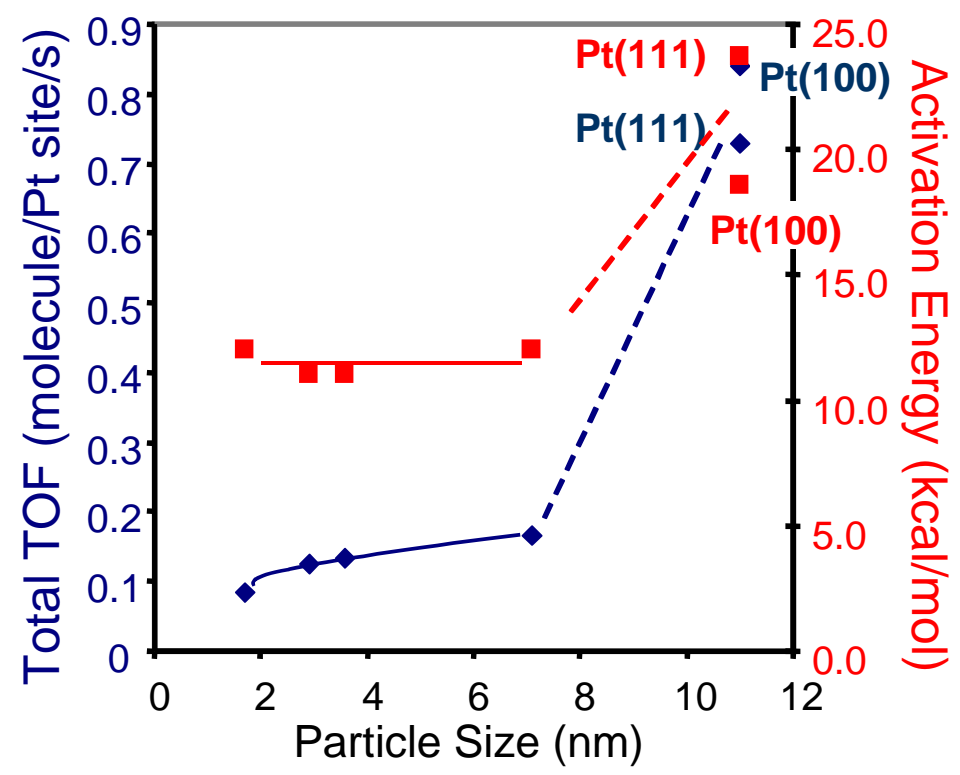

Figure 9. Turnover rate and activation energy over $\mathrm{Pt}$ nanoparticles as a function of particle size in crotonaldehyde hydrogenation. Total turnover rate refers to the sum of product molecules per Pt site per second. All data of (a) were taken at 393 $\mathrm{K}, 1$ Torr $\mathrm{C}_{4} \mathrm{H}_{6} \mathrm{O}, 100$ Torr $\mathrm{H}_{2}$ 


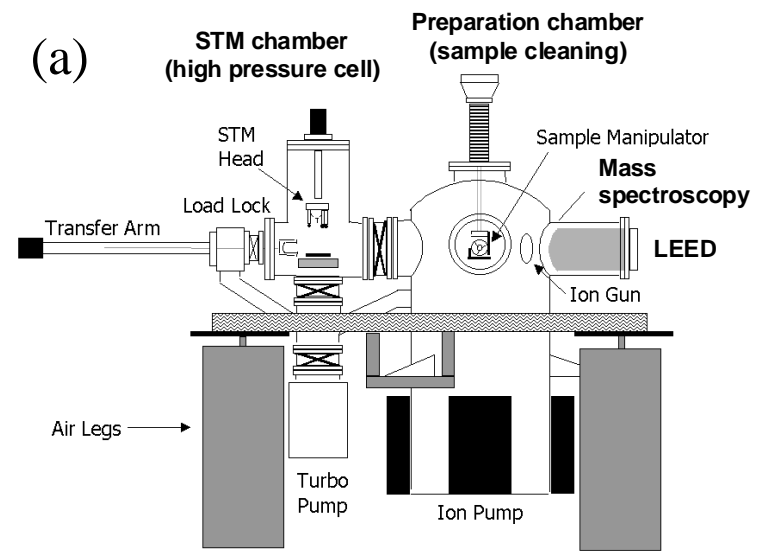

(b)

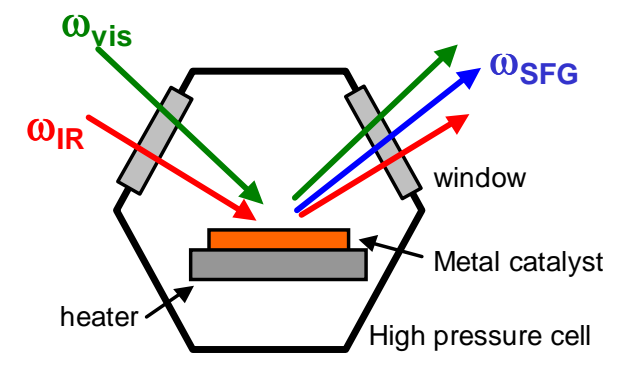

Figure 10. Schematic of (a) high pressure STM and (b) high pressure SFG spectroscopy. 


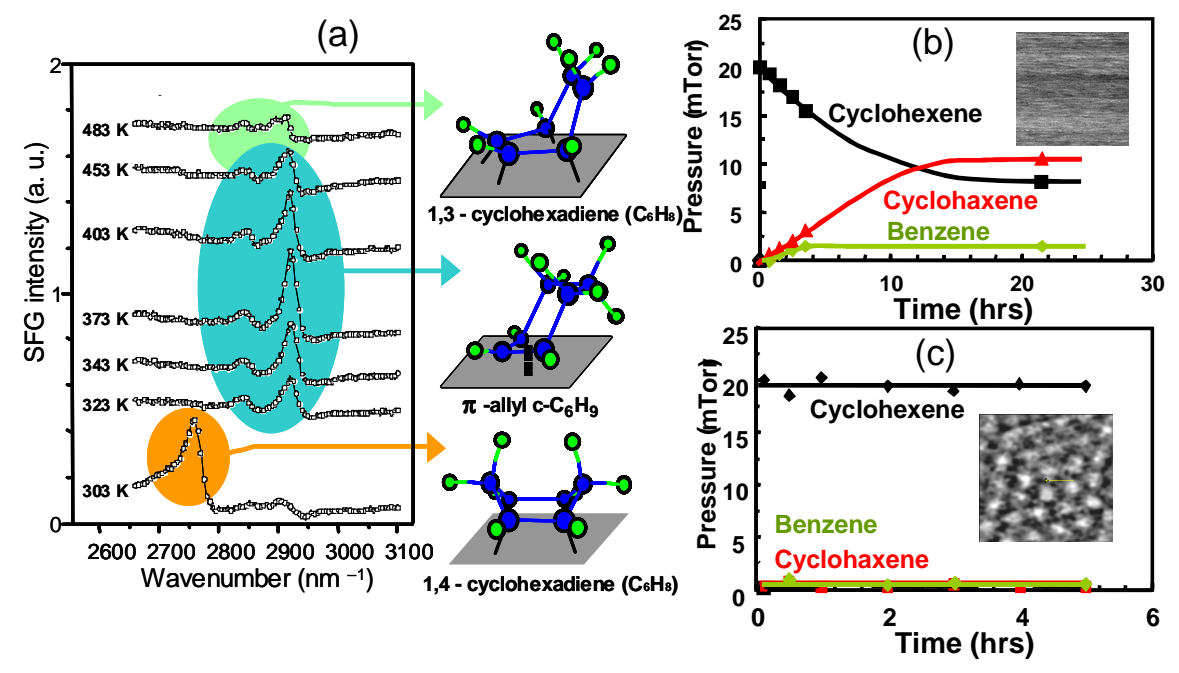

Figure 11. (a) SFG spectrum of the Pt (111) surface during cyclohexene hydrogenation revealing reaction intermediates, 1,4-, 1,3-cyclohexadienes and $\pi$-allyl c- $\mathrm{C}_{6} \mathrm{H}_{9}$.techniques (b) Mass spectrometer study showing the evolution of cyclohexane and benzene at $350 \mathrm{~K}$ produced by the hydrogenation and dehydrogenation of cyclohexene. The inset shows $7.5 \mathrm{~nm} \times 7.5 \mathrm{~nm}$ image of catalytically active $\mathrm{Pt}(111)$ at $300 \mathrm{~K}$ in $200 \mathrm{mTorr}^{\mathrm{H}_{2}}$ and $20 \mathrm{mTorr}$ cyclohexene. (c) Mass spectrometer study showing the evolution of cyclohexane and benzene at $350 \mathrm{~K}$ on $\mathrm{CO}$ poisoned $\mathrm{Pt}$ (111) surface. The inset shows $7 \mathrm{~nm} \times 7 \mathrm{~nm}$ image of $\mathrm{CO}$ poisoned $\mathrm{Pt}(111)$ at $300 \mathrm{~K}$ (in 200 mTorr $\mathrm{H}_{2}, 20$ mTorr of cyclohexene, and 5 mTorr $\mathrm{CO}$ ). 
(a)

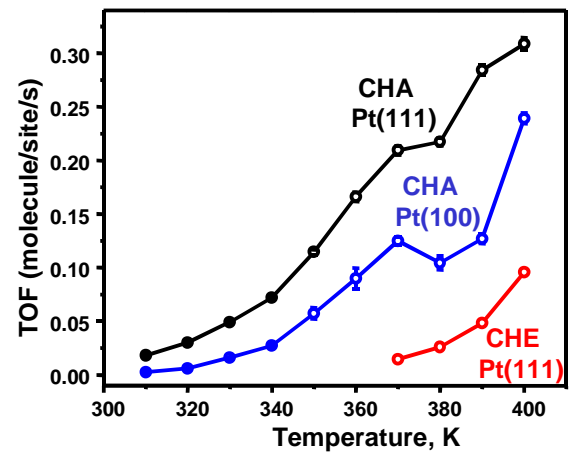

(b)

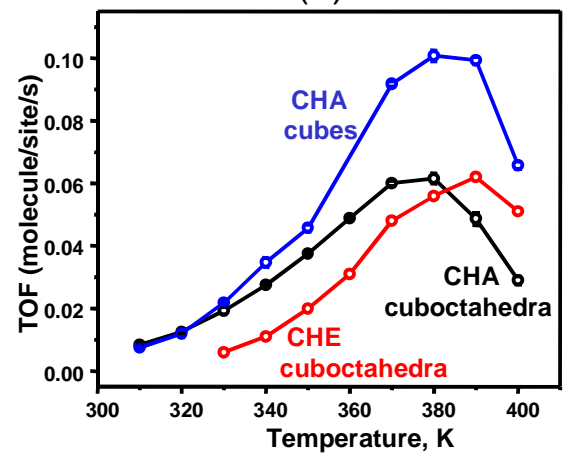

Figure 12. Structural dependence of selectivity in benzene hydrogenation. CHA and CHE refer to cyclohexane and cyclohexene molecules produced under benzene hydrogenation. 


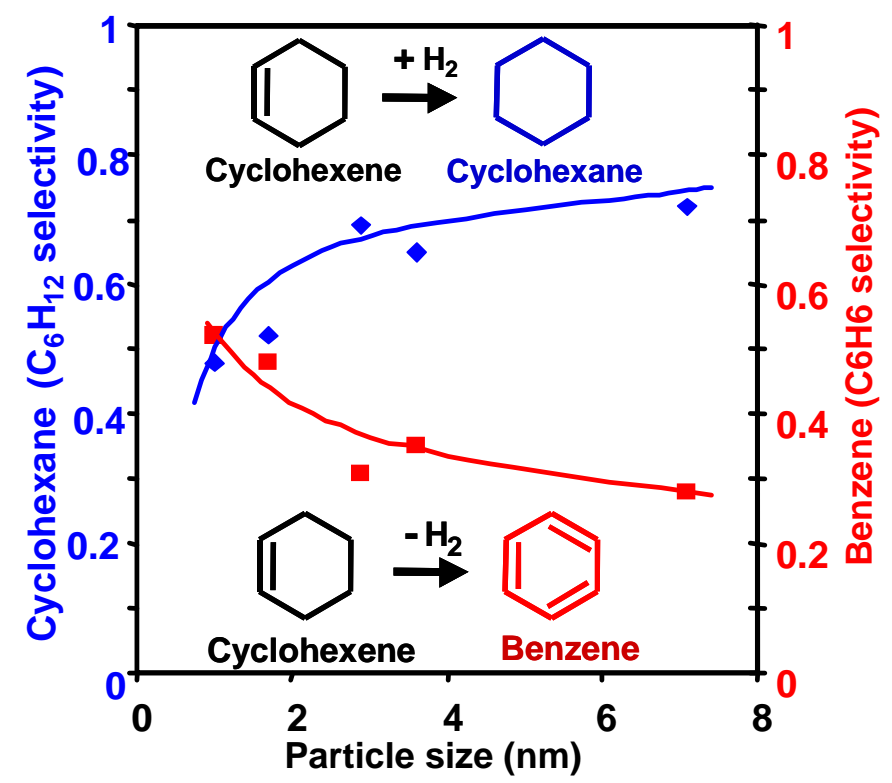

Figure 13. The size dependence of $\mathrm{Pt}$ nanoparticles on the selectivity of cyclohexene hydrogenation / dehydrogenation. 
(a)

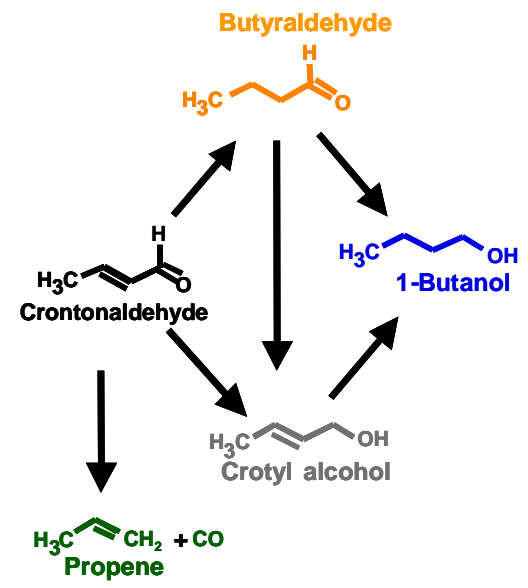

(b)

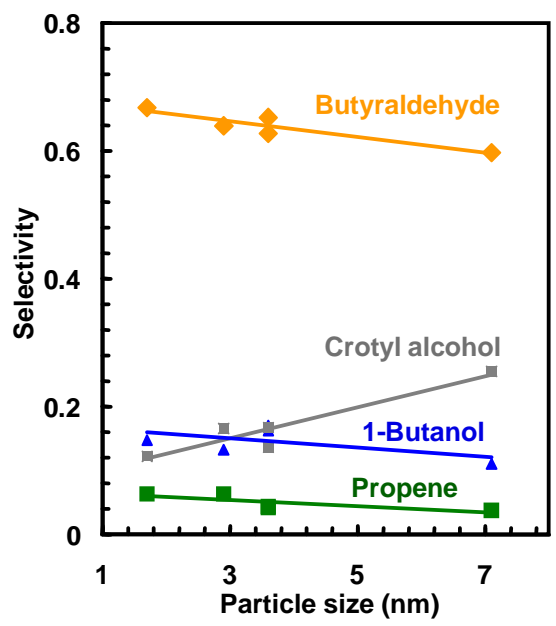

Figure 14. (a) Schematics of multi-path reactions of crotonaldehyde hydrogenation and (b) size dependence of Pt nanoparticle on the selectivity in crotonaldehyde hydrogenation. 

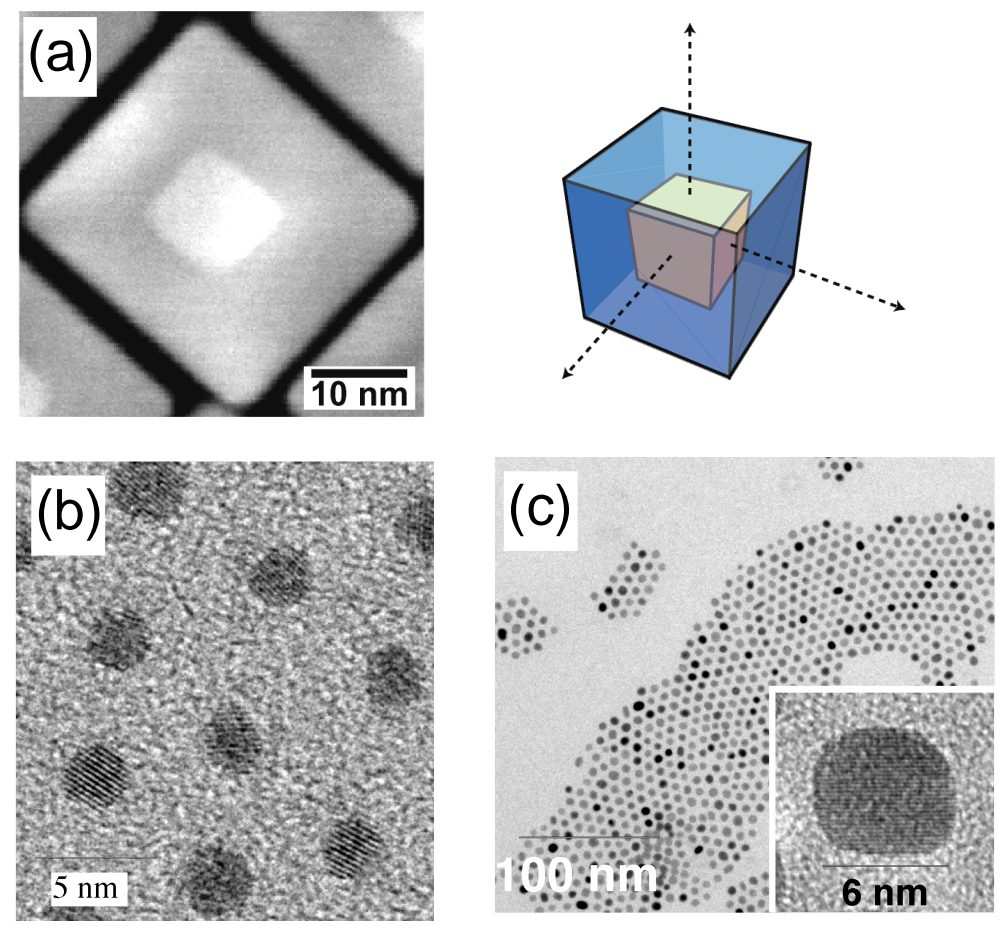

Figure 15. bimetallic nanoparticles with various shape. (a) TEM image of palladium nanoparticles using platinum nanoparticles as seeds. (b) FePt nanoparticle and (c) $\mathrm{CoPt}_{3}$ nanoparticle. 


\section{$\mathrm{Co}_{2}(\mathrm{CO})_{8}$}

$\left.180{ }^{\circ} \mathrm{C}\right] \begin{aligned} & \text { Trioctylphosphine Oxide (TOPO) } \\ & \text { Oleic acid }\end{aligned}$
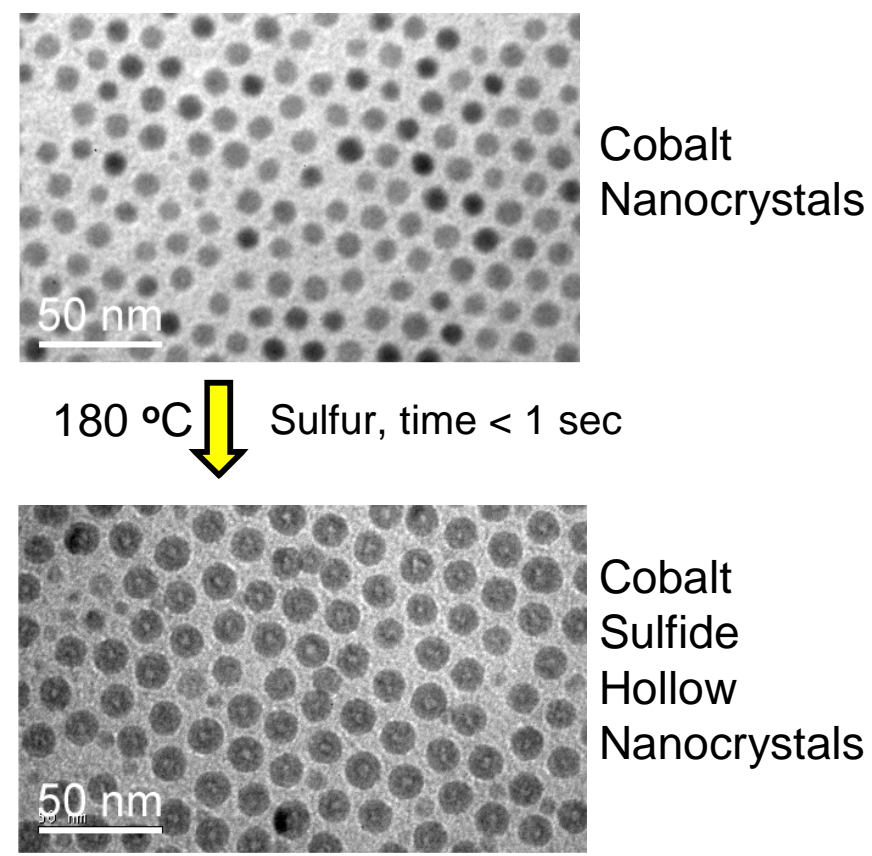

Figure 16. TEM image of cobalt sulfide hollow nanocrystals synthesized with Kirkendall Effect. Uniform cobalt nanocrystals can be synthesized by the rapid pyrolysis of cobalt carbonyl in a hot solvent. The sulfide grows mainly by the outward diffusion of cobalt cations. Hollow cobalt sulfide nanocrystals forms with similar size distribution 

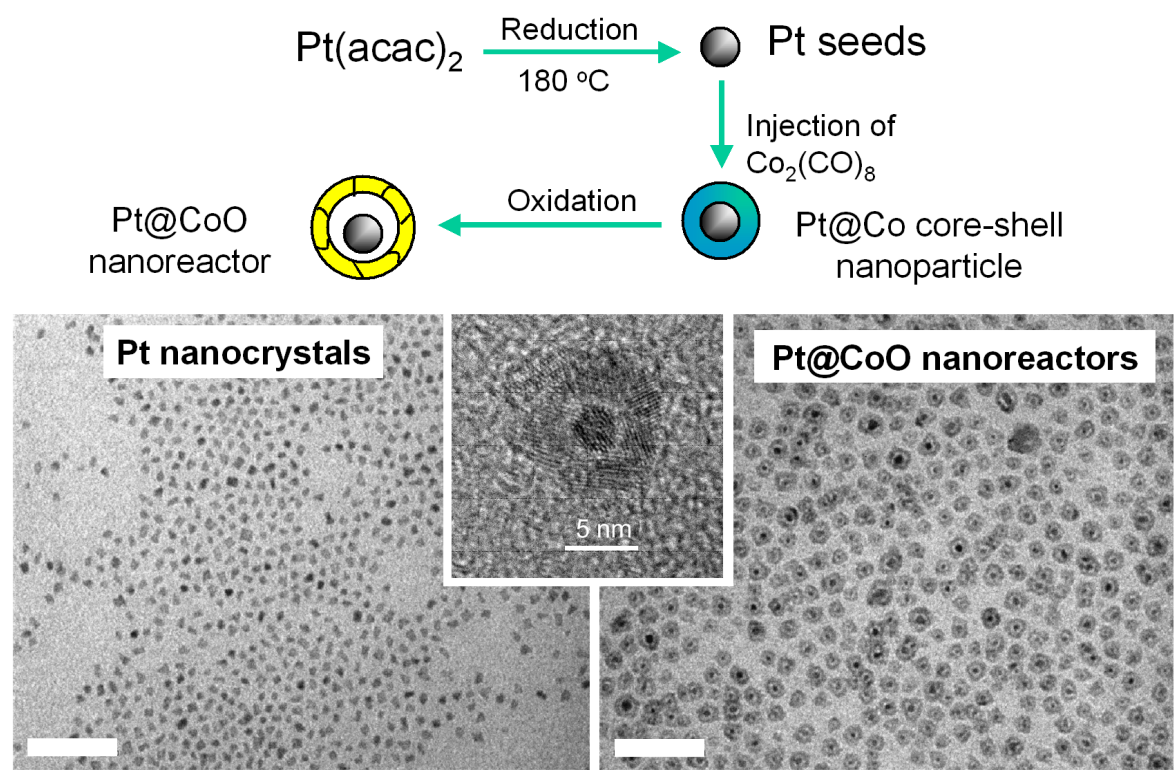

Figure 17. Schematic of synthesis of $\mathrm{Pt} / \mathrm{CoO}$ nanoreactors, and TEM images of $\mathrm{Pt}$ and $\mathrm{Pt} / \mathrm{CoO}$ nanoreactors. The scale bar in TEM images refer to $50 \mathrm{~nm}$. 
(a)

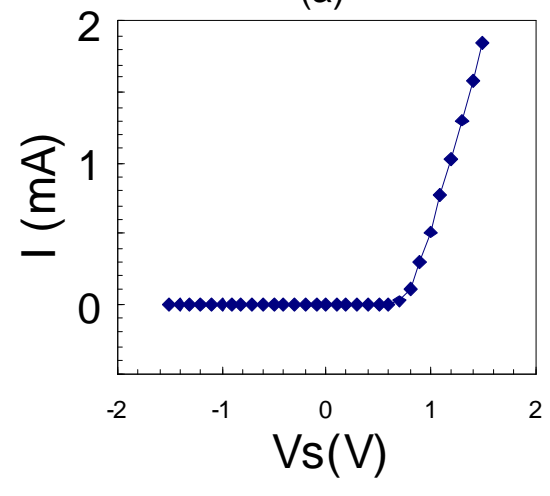

(b)

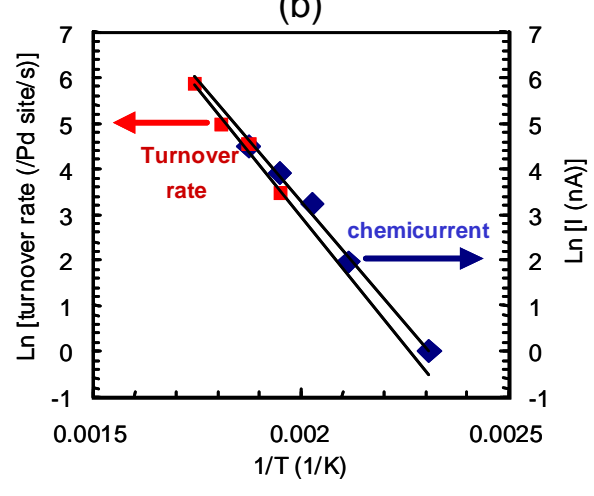

Figure 18. (a) the typical $\mathrm{I}-\mathrm{V}$ curves measured on $\mathrm{Pd} / \mathrm{TiO}_{\mathrm{x}}$ diode. (b) The plot of chemicurrent and turnover rate measured on the $\mathrm{Pd} / \mathrm{TiO}_{\mathrm{x}}$ diode during $\mathrm{CO}$ oxidation (100 Torr of $\mathrm{O}_{2}$ and 40 Torr $\mathrm{CO}$ ) as a function of the temperature. 
(a)

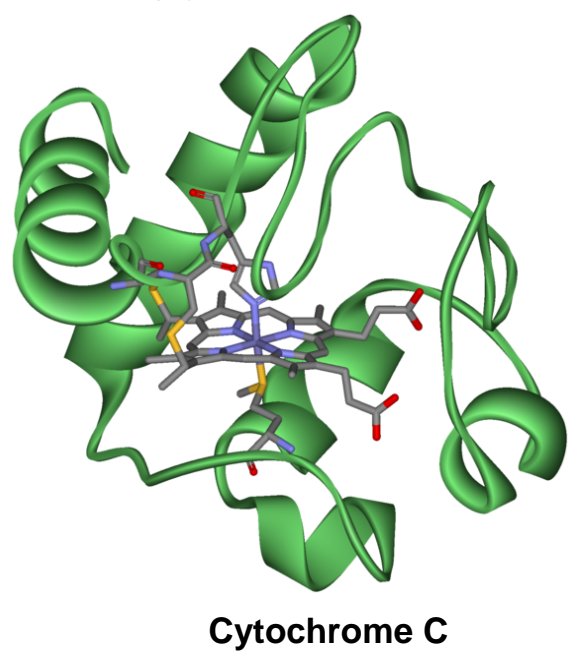

Size: $\sim 4 \mathrm{~nm}, 100$ amino acids Molecular weight: $\sim 12,000$ daltons (b)

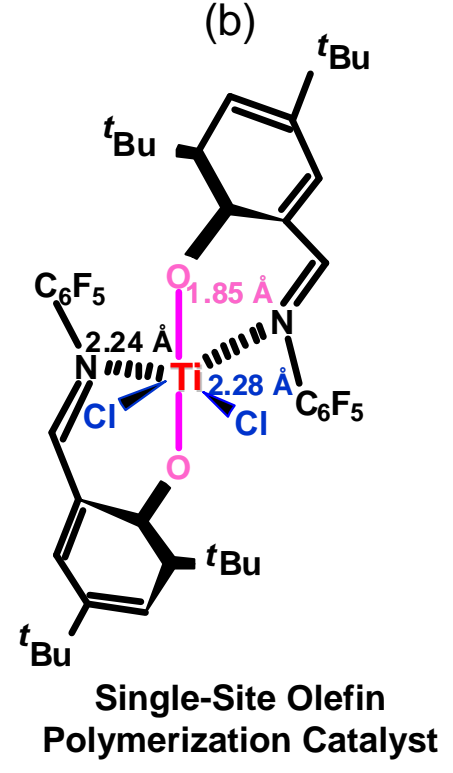

Figure 19. (a) cytochrome $C$ which has a $4 \mathrm{~nm}$ size where the catalytic site outside the protein ligands are $1.4 \mathrm{~nm}$ in size. (b) A single site olefin polymerization catalyst (figure 19b), which is homogeneous, has a $1.6 \mathrm{~nm}$ size. 